American Journal of Pharmaceutical Education 2019; 83 (8) Article 7425.

\title{
COMMENTARY
}

\section{The Case for Culturally Responsive Teaching in Pharmacy Curricula}

\author{
Nicole Rockich-Winston, PharmD, MS, EdS, Tasha R. Wyatt, PhD \\ Medical College of Georgia at Augusta University, Augusta, Georgia \\ Submitted October 25, 2018; accepted May 29, 2019; published October 2019.
}

\begin{abstract}
Cultural diversity training in pharmacy education has evolved from standalone lectures to longitudinal courses, service-learning initiatives, rotation experiences and global health opportunities. Cultural competency frameworks have served as the scaffold for cultural diversity training, yet educators in other health care disciplines have called into question the utility of such frameworks and offered cultural humility as an alternative to foster development and lifelong learning. In order to implement and assess outcomes tied to cultural diversity successfully, this commentary discusses the five elements of culturally responsive teaching that will provide the tools necessary to integrate cultural humility across pharmacy curricula. In addition, we address how to approach faculty development to avoid common maladaptations in pedagogical movements and conclude with addressing the salient objectives to evaluate gains in student, institutional, and societal outcomes.
\end{abstract}

Keywords: cultural competency, cultural diversity, cultural humility, culturally responsive teaching

\section{INTRODUCTION}

The diversity of student pharmacists continues to increase, yet the diversity of faculty among schools and colleges of pharmacy has not matched such growth. ${ }^{1-3}$ As Chisholm emphasizes, a diverse environment in both the student body and faculty lends itself to cross-cultural training and cultural diversity opportunities, which leads to growth in professionalism. ${ }^{4}$ Furthermore, as many have discussed, the increasingly diverse population and the presence of drastic health disparities in the United States (US) not only warrants purposeful training of future pharmacists to meet the needs of their communities, but also predicates that faculty are trained to successfully prepare a culturally adept workforce. ${ }^{5-8}$

Although the term "diversity" has been defined in several ways, pharmacy education has adopted definitions that are broad in scope. The American Association of Colleges of Pharmacy (AACP) defines diversity in reference to student pharmacists as individuals "with backgrounds, perspectives, and experiences that reflect the diverse communities they serve" while the American College of Clinical Pharmacists (ACCP) advocates for diversity to encompass "not only race and ethnicity but also socioeconomic status, rural and urban background, age, gender, sexual orientation, ability level, and other life experiences." $", 10$ For the context of this commentary,

Corresponding Author: Nicole Rockich-Winston, Medical College of Georgia at Augusta University, $112015^{\text {th }}$ St., CB 3630, Augusta, GA 30912. Tel: 706-721-1915. Fax: 706-7212347. E-mail: nwinston@augusta.edu. "cultural diversity," adds another layer to the concept of diversity. Culture can be defined as a fluid, multivariable process "through which ordinary activities and conditions take on an emotional tone and a moral meaning" for individuals. ${ }^{11}$ Thus, the development of student pharmacists as culturally proficient clinicians should result in a workforce that embraces the context and uniqueness of the communities they serve.

The Accreditation Council for Pharmacy Education (ACPE), and other pharmacy related organizations like ACCP, the American Pharmacists Association (APhA), and American Society of Health-System Pharmacists (ASHP) have acknowledged and advocated for cultural diversity training for pharmacy students and current pharmacists. ${ }^{12-15}$ Unequivocally, pharmacy schools and colleges have attempted to achieve this in a myriad of ways; however, these previous approaches have demonstrated several shortcomings because they lack a strong conceptual framework to create transformative change. This commentary begins with a critique of the most commonly used approaches for incorporating cultural diversity into pharmacy education and offers a new approach for thinking about and addressing this important aspect of our changing profession.

\section{Cultural Diversity Training in Pharmacy Education}

The earliest calls for cultural diversity training in pharmacy began in the 1990s and initially emphasized the need for training the pharmacy workforce to provide "pharmaceutical care" to an ever-increasingly diverse population. ${ }^{5,16}$ This call largely translated the 


\section{American Journal of Pharmaceutical Education 2019; 83 (8) Article 7425.}

pharmacists' growing awareness for the need to develop a body of knowledge around alternative health beliefs and appropriate communication strategies for new cultural communities. ${ }^{16}$ ACPE soon recognized the importance of this skillset in graduating pharmacy students and began requiring a school's pre-professional curricula to address culturally diverse training, while the most recent standards require specific outcome data tied to our students' recognition of social determinants of health and cultural awareness. ${ }^{12,17}$

In response, pharmacy educators initiated several approaches to incorporating cultural diversity concepts into their respective curricula. Early efforts included adding supplementary lectures to the curriculum on cultural diversity; whereas, others began creating semester-long courses that addressed issues of cultural diversity or integrating content throughout semester curricula. ${ }^{8,18-22}$ These piecemeal approaches focused primarily on providing content to students, so that they could become more culturally aware. However, these approaches proved to be problematic. While some efforts emphasized an anthropological approach to introducing culture, other approaches described conventional characteristics of races and/or ethnicities common in the US, which proved to be problematic in other health care disciplines. ${ }^{23,24}$

More recently, programs have recognized the importance of training students to engage in reflective inquiry when coming into contact with other racial and ethnic communities. For example, one pharmacy program aimed to achieve this by helping students use open-ended, explanatory models to gain insight into cultural experiences that may influence a patient's health and well-being. ${ }^{20}$ Others have initiated service-learning opportunities within their programs, which are designed to enrich a student's appreciation of civic, cultural, and social issues affecting the surrounding community. ${ }^{25,26}$ Still others attempt to achieve this by offering rotation opportunities and global health outreach to engage students in diverse cultural environments. ${ }^{27,28}$ These approaches have greater potential to be transformative because they compel students to consider the role of culture in health and treatment. Although efforts in service learning, rotational experiences, and global health training are honorable, the absence of a defined meaning of "global health" and disparities among pharmacy schools and colleges make it difficult to quantify the influence of these experiences on the cultural diversity development and appreciation of pharmacy students. ${ }^{27,29}$ Thus, from a broad perspective, our Academy has embraced a multifaceted approach to cultural diversity training, with an increased awareness that students need more than just content to understand the role of culture in health and well-being.

\section{Cultural Diversity Frameworks in Pharmacy Education}

To date, health sciences education has inexplicably linked cultural diversity training to issues of cultural competency, a link that is clearly seen in pharmacy education. The working definition of cultural competency has evolved over time; however, one of the most recent interpretations encompasses an appreciation for diverse beliefs, values and behaviors as a way to tailor patient care based on cultural, social and linguistic needs. ${ }^{30}$ The goal in using this framework is to develop students' knowledge, skills, and attitudes that will help them reach a pinnacle of "cultural competency." $31-33$ However, the critique that is often made in linking cultural competency and cultural diversity is that students are trained using a fixed body of knowledge, skills and attitudes that can be simply demonstrated. ${ }^{34}$ Using a cultural competency framework to support cultural diversity underemphasizes the importance of training students in a way that allows for cognitive flexibility that can be used in varying cultural contexts and communities. ${ }^{34}$

With respect to outcomes, many programs and the educational literature have tied cultural competency closely with health disparities. An unfortunate side effect of integrating cultural competency training with health disparities has resulted in health professional students relating terms linked to cultural diversity to negative experiences or outcomes. ${ }^{35}$ More importantly, concrete outcomes like the elimination of health disparities in the US, have not been demonstrated, nor have significant improvements been mentioned in the literature with current approaches. On the contrary, a recent analysis of data available through the National Center for Health Statistics from 1999 to 2016 indicated significantly higher mortality rates among non-Hispanic black men and women, and, although the trend had been downward, researchers have seen recent evidence of it trending upward. ${ }^{36}$

Clearly, reducing health disparities is multifaceted. However, in order to reverse the recent, troubling trends, cultural diversity training is a crucial component of improving patient care. In response to the critiques involving cultural competency, medical education has coined the term "cultural humility" to encompass a lifelong journey towards appreciating cultural diversity and encourages self-reflection among learners. ${ }^{34}$ Cultural humility has been described as an ideal approach to ensuring pharmacy students are adequately prepared for diverse communities because it emphasizes positionality and the relationship between the pharmacist and the community member. ${ }^{7}$ It emphasizes the practice of self-reflection and self-critique as part of a personal quality improvement 


\section{American Journal of Pharmaceutical Education 2019; 83 (8) Article 7425.}

process as well as learning from patients, partnershipbuilding with others, and a lifelong commitment to appreciating the cultural context in which patients live. ${ }^{37}$ In other words, pharmacists who practice using the principles of cultural humility would be acutely aware of the cultural dynamics and needs in their immediate community, would be able to adapt to an individual patient's needs, and would be reflecting continuously on their interactions to improve patient outcomes.

However, the difficulty with adopting cultural humility in health care curricula, and in pharmacy education specifically, is a lack of tangible models or curricular structures to implement cultural humility curriculum and assess student growth in cultural humility either qualitatively or quantitatively. Although several disciplines have offered theoretical models to integrate cultural humility into curricula, such frameworks have yet to be implemented and evaluated for appreciable outcomes. ${ }^{37,38}$ This is in addition to the fact that cultural competency models emphasize tangible skills that remain crucial for student development as they become practicing pharmacists.

Adopting a blended model that incorporates cultural humility with cultural competency may afford students a well-balanced approach to cultural diversity training. Frameworks that rely on developing students' cultural competency could focus on content and skill development while cultural humility has potential to serve as the scaffolding of the educational environment. This combined approach would allow for both student pharmacists and faculty to address the deeper constructs of cultural diversity and would provide the groundwork for professionals in all areas of health science education to develop the expected professional attitudes and behaviors.

\section{Culturally Responsive Teaching as a Bridge Between Frameworks}

If pharmacy education were to integrate cultural humility and cultural competency in the curriculum, the issue of faculty training must be addressed. Ultimately, success of this approach would hinge on a faculty member's ability to tie these two constructs together. One solution is to frame faculty development using these principles that are embodied in "culturally responsive teaching," in which educators teach "to and through cultural diversity." ${ }^{39,40}$ In this approach, educators use students' cultural knowledge, prior experiences, frames of reference, and performance styles to add both relevance to topics and infuse culture into the classroom. ${ }^{39}$ Research on the use of culturally responsive teaching has demonstrated marked improvements in classroom climate and student cultural humility; therefore, it may be a viable vehicle for implementing a blended approach to infusing curricula with cultural diversity. ${ }^{41-43}$ Thus, the appeal in adopting culturally responsive teaching as a pedagogy is its ability to address cultural diversity training of student pharmacists, improve school environments and conceivably reduce student achievement disparities.

Using culturally responsive teaching in a learning environment is comprised of five essential elements for educators to espouse: create opportunities for cultural socialization, adopt diverse teaching strategies to meet student needs, learn the cultural diversity of the classroom, develop culturally relevant curricula, and demonstrate cultural compassion. ${ }^{44}$ Cultural diversity educators in pharmacy education have demonstrated and championed the first two aspects of culturally responsive teaching, which is evidenced by the multitude of opportunities that students have available for cultural socialization with diverse communities. ${ }^{22,25-28,45}$ As an example, pharmacy educators who incorporate elements of community outreach, service-learning, or global health outreach into their courses have created an environment that lends itself to cultural socialization. Moreover, educators who have incorporated teaching strategies in the classroom that engage learners using technology, case studies, group exercises, etc., have provided several modalities for students to learn. The latter three elements, however, need to be explored further.

Research shows that pharmacy educators have difficulty implementing the third element: learning the cultural diversity of the class. ${ }^{46,47}$ For example, a survey that evaluated health care educators, including pharmacy educators, found that $70 \%$ of respondents reported a lack of training to teach culturally diverse students. ${ }^{47}$ In addition, pharmacy educators, especially those in basic sciences, may also struggle to develop culturally relevant curricula, the fourth element in culturally responsive teaching. Basic science faculty may contend that incorporating cultural content or creating opportunities for students to connect with the community may be beyond the scope of their courses. However, culturally relevant teaching has been successfully adopted by several STEM educators in secondary and higher education. ${ }^{48,49}$ As an example, introducing student pharmacists to the pharmacology of belladonna alkaloids by describing the ingredients used in "zombie's cucumber" by Haitian voodoo priests provides opportunities to learn characteristics about the drugs and initiates fascinating discussions surrounding the Haitian culture. ${ }^{50}$ Thus, encouraging faculty in all disciplines to incorporate aspects of various cultures and ethnic groups can reinforce an institution's commitment to cultural diversity training. 


\section{American Journal of Pharmaceutical Education 2019; 83 (8) Article 7425.}

The final element of culturally responsive teaching requires a commitment from faculty to demonstrate cultural compassion. Typically, demonstrating cultural compassion requires faculty to model appropriate cultural interactions and behaviors when interacting with people from another culture. Findings in both medical and pharmacy education have demonstrated that interactions, informal messages, and treatment among students can be at odds with the formal cultural diversity training that institutions provide. ${ }^{51,52}$ Even worse, discriminatory comments made by faculty members can create unhealthy classroom environments and perpetuate the denigrating practice of not valuing diversity in a way that extends beyond the classroom. ${ }^{53}$ Efforts in higher education have largely been limited to online modules or "one-and-done" faculty development sessions. ${ }^{54}$ However, the impact of such comments and interactions underscore the importance and need for a strong faculty development effort.

\section{Faculty Perspectives on Cultural Diversity and Fac- ulty Development}

From an implementation standpoint, training faculty to become culturally responsive educators begins with assessing faculty perspectives on cultural diversity. ${ }^{43}$ Sleeter indicates that faculty perspectives can vary from a deficient-oriented approach to an emancipatory one. ${ }^{43}$ A deficit-oriented approach posits that students' backgrounds correlate with their achievement. ${ }^{43}$ For example, some educators may believe that students from diverse backgrounds are inhibited to achieving certain standards based on their upbringing. More specifically, an educator who adopts a deficit-oriented approach may expect Asian American students to perform well because their culture emphasizes academic excellence. This approach is fundamentally flawed and would not support the development of student pharmacists with respect to the four tenets of cultural humility or embody the five elements of culturally responsive teaching.

Structural approaches, on the other hand, seek to reduce organizational barriers to equalize opportunities for students. ${ }^{43}$ Educational opportunities and resources include ensuring students have access to a rigorous, well-instructed curriculum and consistent expectations. ${ }^{43}$ Our current process for training student pharmacists about cultural diversity is a structural-oriented approach. Culturally-related courses, service-learning, and global health initiatives provide culturally diverse experiences to student pharmacists across our Academy. Thus, an educator who adopts a structural approach would maximize resources dedicated to cultural diversity training and expect all students to achieve a particular level of competence. Although this approach may embrace aspects of cultural humility, concrete outcomes, like reductions in health disparities as discussed earlier, have yet to be realized. ${ }^{36}$

Alternatively, educators who adopt an emancipatory approach celebrate student diversity and see it as an asset. ${ }^{43}$ In the context of pharmacy education, an educator who espouses an emancipatory approach would encourage students to first reflect on how their culture has played a role in their well-being and then would lead a discussion using student-generated experiences. An emancipatory approach is powerful because it emphasizes the four tenets of cultural humility that were previously described: self-reflecting/self-critiquing, learning from patients, creating a patient-practitioner partnership, and embracing a lifelong process. ${ }^{37}$ Additionally, this approach prepares educators to adopt culturally responsive teaching practices within their classrooms. ${ }^{43}$ Moving toward this approach would necessitate that faculty both embrace and adopt an emancipatory approach to education across the curriculum.

Designing robust training initiatives for faculty is crucial to meet our current diversity challenges in a way that is responsive to the changing demographics in the US. Standalone workshops have not demonstrated evidence reflecting changes in educators' approaches and influencing particular student outcomes. ${ }^{55}$ Rather, well-defined faculty development programs must encompass "best practices." 55,56 One of the best forms of faculty development is known as "shadow coaching," in which mentors support individual educators by providing feedback regularly in the classroom and encourage instructors to reflect and self-critique on their goals, teaching, and forms of assessment. ${ }^{43}$ Shadow coaching also involves groups of mentors and mentees meeting regularly as a part of this process to reflect collaboratively on their experiences and develop solutions to problems arising in their respective courses. ${ }^{43}$ It is the purposeful and targeted follow-up after ongoing faculty peerobservations that helps ensure that faculty implement effective teaching models, but also avoid maladaptation of key elements which could result in unintended variations of culturally responsive teaching. ${ }^{57}$

Sources of mentors equipped to provide shadow coaching at a school or college of pharmacy include faculty who have pursued additional training in education, completing coursework through colleges or departments of education toward certificates or degrees. For example, many Doctor of Education programs offer concentrations in areas like curriculum or instruction that introduce educators to curricular theories that often include culturally responsive pedagogy. ${ }^{58}$ 


\section{American Journal of Pharmaceutical Education 2019; 83 (8) Article 7425.}

In addition, pharmacy educators can reach out to university-wide institutions like centers for teaching and learning to request mentors who have been trained in culturally responsive teaching. From an evaluation perspective, the Teaching Multicultural Attitude Survey, the Multicultural Teaching Competency Scale, and culturally responsive teaching rubrics like those designed by Kea and Trent provide salient resources to augment culturally responsive strategies for faculty members. ${ }^{59-61}$

\section{Student and Patient Outcomes}

The final challenge in adopting culturally responsive teaching in our classrooms is to assess tangible outcomes on a curricular, institutional and societal level. With respect to pharmacy curricula, student and peer evaluations, observations, and teaching portfolios can serve as evidence of pedagogical implementation. On a more granular level, improvements in student scores collectively and individual improvements in "at-risk" students should emerge because of the growing evidence that student achievement increases when educators embrace culturally responsive teaching practices. ${ }^{43}$ When considering school outcomes, assessing school climate is warranted. Collecting data from focus groups to evaluate cultural awareness of faculty and students will provide a baseline and ongoing data streams for assessment. ${ }^{52}$ By implementing the elements of culturally responsive pedagogy, pharmacy schools and colleges should observe reductions in culturally insensitive behavior among faculty and students.

Lastly, monitoring trends in health disparities through organizations like the National Center for Health Statistics and identifying declines in health disparities among marginalized patient populations is a long-term data set for our Academy to assess success with respect to culturally responsive teaching implementation. Pharmacy schools and colleges can also monitor and assess trends in local health disparity data provided by health departments. Even more, creating purposeful community-based research initiatives similar to recent endeavors described by Minkler will provide data sources to identify incremental changes in health disparities among our communities. ${ }^{62}$ These opportunities will inspire students, faculty, and administrators to boost efforts in training future pharmacists from a cultural humility perspective.

\section{CONCLUSION}

If we assume that our nation will continue to increase in diversity and if, as a profession, we value cultural competency among our pharmacy graduates, then schools and colleges of pharmacy must create and rely on a viable framework that will help us reach our goals. This commentary furthers the notion that if pharmacy schools and colleges invest in training faculty to use "culturally responsive teaching" methods, then, as a community, we would be able to instill the four tenets of cultural humility in our students and reach our collective goal of improving the educational learning environment for students while simultaneously working to reduce health disparities in the community.

As an Academy, we have an opportunity to provide leadership among the health care disciplines in creating a culturally sensitive and responsive workforce, but this requires that we consider new approaches and frameworks, some of which are drawn from other disciplines. Although the steps for successful implementation of faculty development, cultural humility, and culturally responsive teaching may seem arduous, the process must begin by positioning culture in the forefront of our educational efforts and providing the right frameworks to ensure we reach our goals.

Table 1. Key Attributes of Cultural Competency and Cultural Humility ${ }^{31-34}$

\section{Cultural Competency}

Central Tenets

A sound educational foundation about diverse cultural and ethnic groups leads to culturally competent professionals

Training

Develops personal awareness, knowledge, skills, comfort level, and attitudes toward care for culturally diverse patient populations

\section{Overall Goal}

Negotiate and restructure therapeutic plans based on the culturally diverse beliefs and behaviors of the patient

\section{Cultural Humility}

A lifelong commitment to self-reflection and redressing power imbalances leads to patientcentered, culturally sound health care encounters

Develops personal awareness, flexibility, empathy, and mindfulness toward an interpersonal stance that is patient-centered in relation to aspects of personal and cultural identity

Relinquish a provider's role as a cultural expert and adopt patient-centered interviewing to create a mutual therapeutic alliance 


\section{American Journal of Pharmaceutical Education 2019; 83 (8) Article 7425.}

\section{REFERENCES}

1. Hagan AM, Campbell HE, Gaither CA. The racial and ethnic representation of faculty in US pharmacy schools and colleges. $\mathrm{Am} J$ Pharm Educ. 2016;80(6):Article 108.

2. Hayes B. Increasing the representation of underrepresented minority groups in US colleges and schools of pharmacy. Am J Pharm Educ. 2008;72(1):Article 14.

3. Nkansah NT, Youmans SL, Agness CF, Assemi M. Fostering and managing diversity in schools of pharmacy. Am J Pharm Educ. 2009;73(8):Article 152.

4. Chisholm MA. Diversity: a missing link to professionalism. Am J Pharm Educ. 2004;68(5):Article 120.

5. Brown CM, Doan QD. Pharmacy students' perceptions about the need for multicultural education. Am J Pharm Educ. 1998;62(3):310315 .

6. Mullins CD, Blatt L, Gbarayor CM, Yang H-WK, Baquet C. Health disparities: a barrier to high-quality care. Am J Health Syst Pharm. 2005;62(18):1873-1882.

7. Shaya FT, Gbarayor CM. The case for cultural competence in health professions education. Am J Pharm Educ. 2006;70(6):Article 124.

8. Westberg SM, Bumgardner MA, Lind PR. Enhancing cultural competency in a college of pharmacy curriculum. Am J Pharm Educ. 2005;69(5):Article 82.

9. O’Connell MB, Jackson AN, Karaoui LR, et al. Cultural competency in health care and its implications for pharmacy part 3B: emphasis on pharmacy education policy, procedures, and climate.

Pharmacotherapy. 2013;33(12):e368-e381.

10. White C, Conway JM, Davis PK, et al. AACP special taskforce white paper on diversifying our investment in human capital. Am J Pharm Educ. 2017;81(8):S13.

11. Kleinman A, Benson P. Anthropology in the clinic: the problem of cultural competency and how to fix it. PLoS Med.

2006;3(10):e294.

12. Accreditation Council for Pharmacy Education. Accreditation standards and key elements for the professional program in pharmacy leading to the doctor of pharmacy degree. (Standards 2016). https:// www.acpe-accredit.org/pdf/Standards2016FINAL.pdf. Accessed September 1, 2018.

13. Gibson RD. Advice from a walrus. JAPhA. 2000;40(5):S15-S18. 14. O'Connell MB, Korner EJ, Rickles NM, Sias JJ. Cultural competence in health care and its implications for pharmacy. Part 1. Overview of key concepts in multicultural health care.

Pharmacotherapy. 2007;27(7):1062-1079.

15. Vanderpool H. Report of the ASHP ad hoc committee on ethnic diversity and cultural competence. Am J Health Syst Pharm. 2005;62(18):1924-1930.

16. Lecca PJ, Osemene N, Jackson D. Pharmaceutical care in a culturally diverse society. US Pharm. 1997;22:70-86.

17. American Council on Pharmaceutical Education. Accreditation standards and guidelines for the professional program in pharmacy leading to the doctor of pharmacy degree. Adopted June 14, 1997. http://www.acsu.buffalo.edu/ sauberan/pdf/

gam_standards_2000.pdf. Accessed September 1, 2018.

18. Onyoni EM, Ives TJ. Assessing implementation of cultural competency content in the curricula of colleges of pharmacy in the United States and Canada. Am J Pharm Educ.

2007;71(2):Article 24.

19. Assemi M, Cullander C, Hudmon KS. Implementation and evaluation of cultural competency training for pharmacy students. Ann Pharmacother. 2004;38(5):781-786.
20. Evans E. An elective course in cultural competence for healthcare professionals. Am J Pharm Educ. 2006;70(3): Article 55. 21. Cailor SM, Chen AMH. Immediate and longitudinal effects of incorporating health literacy and cultural competency into a yearlong pharmacy curriculum. Curr Pharm Teach Learn. 2015;7(3):292-301. 22. Poirier TI, Butler LM, Devraj R, Gupchup GV, Santanello C, Lynch JC. A cultural competency course for pharmacy students. Am J Pharm Educ. 2009;73(5):Article 81.

23. Schiele JH. Implications of the equality-of-oppressions paradigm for curriculum content on people of color. J Soc Work Educ. 2007;43(1):83-100.

24. Solorzano DG. Images and words that wound: critical race theory, racial stereotyping, and teacher education. Teach Educ $Q$. 1997;24(3):5-19.

25. Brown B, Heaton PC, Wall A. A service-learning elective to promote enhanced understanding of civic, cultural, and social issues and health disparities in pharmacy. Am J Pharm Educ.

2007;71(1):Article 9.

26. Roche VF, Jones RM, Hinman CE, Seoldo N. A service-learning elective in Native American culture, health and professional practice. Am J Pharm Educ. 2007;71(6):Article 129.

27. Bailey LC, DiPietro Mager NA. Global health education in doctor of pharmacy programs Am J Pharm Educ. 2016;80(4):Article 71. 28. Haack S. Engaging pharmacy students with diverse patient populations to improve cultural competence. Am J Pharm Educ. 2008;72(5):Article 124.

29. Liu Y, Zhang Y, Liu Z, Wang J. Gaps in studies of global health education: an empirical literature review. Glob Health Action.

2015;8:25709.

30. Betancourt JR, Green AR, Carrillo JE, Ananeh-Firempong O, 2nd. Defining cultural competence: a practical framework for addressing racial/ethnic disparities in health and health care. Public Health Rep. 2003;118(4):293-302.

31. Campinha-Bacote J. A model and instrument for addressing cultural competence in health care. J Nurs Educ. 1999;38(5):203-207. 32. Leininger MM. Leininger's theory of nursing: cultural care diversity and universality. Nurs Sci Q. 1988;1(4):152-160. 33. Purnell L. The Purnell model for cultural competence. J Transcult Nurs. 2002;13(3):193-196.

34. Tervalon M, Murray-Garcia J. Cultural humility versus cultural competence: a critical distinction in defining physician training outcomes in multicultural education. J Health Care Poor Underserved. 1998;9(2):117-125.

35. Nazar M, Kendall K, Day L, Nazar H. Decolonising medical curricula through diversity education: lessons from students. Med Teach. 2015;37(4):385-393.

36. Bilal U, Diez-Roux AV. Troubling trends in health disparities. N Engl J Med. 2018;378(16):1557-1558.

37. Chang ES, Simon M, Dong XQ. Integrating cultural humility into health care professional education and training. Adv Health Sci Educ. 2012;17(2):269-278.

38. Fisher-Borne M, Cain JM, Martin SL. From mastery to accountability: cultural humility as an alternative to cultural competence Soc Work Educ. 2015;34(2):165-181.

39. Gay G. Culturally Responsive Teaching: Theory, Research, and Practice. 2nd ed. New York: Teachers College; 2010.

40. Ladson-Billings G. Culturally Relevant Teaching. Ohio: Ohio State University's College of Education; 1995.

41. Epstein T, Mayorga E, Nelson J. Teaching about race in an urban history class: the effects of culturally responsive teaching. J Soc Stud Res. 2011;35(1):2-21. 


\section{American Journal of Pharmaceutical Education 2019; 83 (8) Article 7425.}

42. Larson KE, Pas ET, Bradshaw CP, Rosenberg MS, Day-Vines NL. Examining how proactive management and culturally responsive teaching relate to student behavior: Implications for measurement and practice. School Psych Rev. 2018;47(2):153166.

43. Sleeter CE. Professional Development for Culturally Responsive and Relationship-Based Pedagogy. New York: Peter Lang; 2011.

44. Gay G. Preparing for culturally responsive teaching. $J$ Teach Educ. 2002;53(2):106-116.

45. Vyas D, Caligiuri FJ. Reinforcing cultural competency concepts during introductory pharmacy practice experiences. Am J Pharm Educ. 2010;74(7):Article 129.

46. Assemi M, Mutha S, Hudmon KS. Evaluation of a train-thetrainer program for cultural competence. Am J Pharm Educ. 2007;71(6):Article 110.

47. Mantzourani E, Courtier N, Davies S, Bean G. Perceptions of faculty in health care and social sciences on teaching international students. Curr Pharm Teach Learn. 2015;7(5):635-644.

48. Jabbar A, Hardaker G. The role of culturally responsive teaching for supporting ethnic diversity in British university business schools. Teach High Educ. 2013;18(3):272-284.

49. Kant JM, Burckhard SR, Meyers RT. Engaging high school girls in Native American culturally responsive steam enrichment activities. J STEM Educ. 2018;18(5):15.

50. Albuquerque UP, Melo JG, Medeiros MF, et al. Natural products from ethnodirected studies: revisiting the ethnobiology of the zombie poison. Evid Based Complement Alternat Med.

2012;2012:1-19.

51. Murray-Garcia JL, Garcia JA. The institutional context of multicultural education: what is your institutional curriculum? Acad Med. 2008;83(7):646-652.
52. Popovich NG, Okorie-Awe C, Crawford SY, et al. Assessing students' impressions of the cultural awareness of pharmacy faculty and students. Am J Pharm Educ. 2018;82(1):Article 6161.

53. Pérez Huber L, Solorzano DG. Racial microaggressions as a tool for critical race research. Race Ethn Educ. 2015;18(3):297-320.

54. Booker KC, Merriweather L, Campbell-Whatley G. The effects of diversity training on faculty and students' classroom experiences. Int J Scholar Teach Learn. 2016;10(1):n1.

55. Guskey TR, Yoon KS. What works in professional development? Phi Delta Kappan. 2009;90(7):495-500.

56. Yoon KS, Duncan T, Lee SW-Y, Scarloss B, Shapley KL. Reviewing the evidence on how teacher professional development affects student achievement: issues \& answers. Reg Educ Lab Southwest 2007;2007(33):62.

57. McLaughlin MW, Mitra D. Theory-based change and changebased theory: going deeper, going broader. J Educ Chang. 2001;2(4):301-323.

58. McCarthy M. Reflections on the evolution of educational leadership preparation programs in the United States and challenges ahead. J Educ Adm. 2015;53(3):416-438.

59. Kea CD, Trent SC. Providing culturally responsive teaching in field-based and student teaching experiences: a case study.

Interdiscip J Teach Learn. 2013;3(2):82-101.

60. Ponterotto JG, Baluch S, Greig T, Rivera L. Development and initial score validation of the Teacher Multicultural Attitude Survey. Educ Psychol Meas. 1998;58(6):1002-1016.

61. Spanierman LB, Oh E, Heppner PP, et al. The Multicultural Teaching Competency Scale: development and initial validation. Urban Educ. 2011;46(3):440-464.

62. Minkler M. Linking science and policy through communitybased participatory research to study and address health disparities. Am J Public Health. 2010;100(S1):S81-S87. 